\title{
Hypertriglyceridemia and its association with Glycated Hemoglobin in Type 2 Diabetes Mellitus - A cross sectional study.
}

\author{
Balaji Vijayam $^{1}$, Taarika Balaji², Madhuri S Balaji ${ }^{1}$, Seshiah Veerasamy ${ }^{1}$, Anitha Rani.A ${ }^{1}$ \\ ${ }^{1}$ Dr. V Balaji Dr. V Seshiah Diabetes Care and Research Institute, Aminjikarai, Chennai, Tamil Nadu, India, ${ }^{2}$ Saveetha Institute \\ of Technical and Medical Sciences, Chennai, Tamil Nadu, India
}

@ Corresponding Author: Dr. Balaji Vijayam, Dr. V Balaji Dr. V Seshiah Diabetes Care and Research Institute, Chennai, Tamil Nadu, India, Phone: +91-9841081010, E-mail: balajivijayam@gmail.com

DOI: 10.29322/IJSRP.11.12.2021.p12043

http://dx.doi.org/10.29322/IJSRP.11.12.2021.p12043

Abstract:

Globally, diabetes mellitus is a common health problem. People with diabetes are at a greater risk of developing cardiovascular disease due to dyslipidaemia. The aim of the present study was to determine the association of Hypertriglyceridemia and Glycated hemoglobin among T2DM individuals. The retrospective, observational study was conducted among T2DM patients with isolated Triglyceride from January 2020 to Oct 2021. A total of 1248 T2DM individuals with Hypertriglyceridemia were included in the study and were assessed for isolated hyper triglyceride and Glycated haemoglobin (HbA1C). Of 1248 patients, 801 (64.18\%) were males and 447 were female (35.81\%). The mean age, duration of diabetes and HbA1C was 56.873 $\pm 12.3 y$ years, $15.87 \pm 5.92$ years and $8.53 \pm 1.78 \%$ respectively. There exist a significant difference in isolated hyper triglyceride among the various age groups, gender and HbA1C. Isolated Triglyceride levels shows a positive correlation with age ( $r=0.219 ; \mathrm{p}=0.000)$, Gender (0.076; $\mathrm{p}=0.008), \mathrm{HbA1C}(\mathrm{r}=0.104 ; \mathrm{p}=0.00)$. The current study finding highlighted that there is a significant association between Hypertriglyceridemia and Glycated haemoglobin in T2DM individuals. The proper control of Glycated haemoglobin might prevent the predisposition of isolated triglyceride and reducing the risk of cardiovascular disease.

Keywords: Hypertriglyceridemia, Isolated triglyceride, Glycated hemoglobin, T2DM.

\section{Introduction:}

In a country like India with its large population and diversified cultural practices and various lifestyle choices, experiences different challenges, specifically when it comes to non-communicable diseases such as Diabetes. Diabetes mellitus (DM) is a major socioeconomic burden and leading cause of morbidity and mortality. According to International Diabetes Federation (IDF, 2019), there are approximately 463 million adults with diabetes, and the number is projected to rise to 700 million by 2045 (1). There are various metabolic disorders associated with diabetes due to decreased insulin resistance. The poor glycaemic control predisposing to the micro vascular and macro vascular complications. Type 2 Diabetes Mellitus (T2DM) is linked with cardiovascular morbidity and mortality. Dyslipidaemia and hypertension are major cardiovascular risk factors in diabetes $(2,3)$. Diabetes patients, particularly those with hyperglycaemia, are commonly affected by hypertriglyceridemia. Triglyceride levels are often accompanied by an increase in non-HDL cholesterol, a combination known as atherogenic dyslipidaemia of diabetes (ADD) (4). In T2DM individuals, elevated blood sugar levels and increased insulin resistance results in increased triglycerides levels, which leads to high production and low clearance of chylomicrons and VLDL (5). 
Insulin resistance is higher in Asian population, when compared to white population as Indians use statin and Aspirin in managing dyslipidemia. Asians have been found to develop cardiovascular conditions at a younger age than other ethnic groups due to older arteries than their chronological age $(6,7)$. Mortality due to cardiovascular disease was higher among age group less than 70 years when compared to greater than 70 years (8). Earlier studies showed that there is a link between hyper triglyceride and increased blood sugar levels $(9,10)$. Recent study showed that significant percent of T2DM patients who received statin therapy have hypertriglyceridemia (11). Thus it is significant to understand the underlying mechanism of insulin resistance and dyslipidaemia predisposing to CVD $(12,13)$. There is a paucity of data on hypertriglyceridemia and its association with HbA1C among T2DM individuals. There is a need to get a clear understanding of disease and its risk factors to facilitate the diagnosis, treatment initiatives and risk factor interventions so as to improve the quality of life. Thus the current study focused to determine the association of hypertriglyceridemia and Glycated hemoglobin among T2DM individuals.

\section{Materials and Methods:}

A retrospective cross sectional study was conducted among the T2DM patients to analyse the prevalence of isolated hyper triglyceride in an outpatient department of a tertiary care centre in Chennai from January 2020 to October 2021. The study subjects were recruited base on inclusion and exclusion criteria. Patient with Diabetes who were mentally oriented, aged between 30 and 80 years of both the genders, T2DM individuals with pre-existing comorbid conditions were included in the study. Those individuals who were on alternative treatment for diabetes and other serious illness pregnant women, patients with incomplete medical records were excluded from the study. Detailed patient history and clinical examination of all the included patients were done. Demographic and clinical characteristics including age, gender, HbA1c, Lipid profile were recorded accordingly. All biochemistry work up (HbA1C, lipid profile) were conducted using D-100 BioRad and Roche Cobas C501 chemistry analyser. Isolated hypertriglyceride was defined as Triglyceride $>200 \mathrm{mg} / \mathrm{dL}$, HDL less than 40mg/dL, LDL $<100 \mathrm{mg} / \mathrm{dL}$, Total cholesterol $<200 \mathrm{mg} / \mathrm{dL}$.

The demographic characteristics were analysed and presented as means, standard deviations, and percentages. Frequency and percentage were calculated and tabulated for demographic variables. The independent sample t-test and analysis of variance (ANOVA) test was used as appropriate for inferential statistics. A p-value of less than 0.05 was considered to be statistically significant. ANOVA test was used to find a correlation between triglyceride and Glycated haemoglobin. Pearson correlation analysis was used to evaluate the relationship between hypertriglyceridemia with age, gender and HbA1c. All data were analysed using SPSS Software version 20 (IBM corp.) P-values less than 0.05 was considered statistically significant.

\section{Results:}

A total of 23,371 patients underwent lipid profile and Glycated haemoglobin during the study period. Out of 23,371 patients, 1248 T2DM patients with Hypertriglyceridemia (all lipid parameters are in normal range, except triglyceride), who fulfilled the inclusion criteria were included in the study. Of 1248 patients, 801 (64.18\%) were males and 447 were female (35.81\%). Majority of the individuals in study population was aged between 50 and 60 years. The mean age and the duration of diabetes was $56.873 \pm 12.3$ years and $15.8 \pm$ years respectively. About $80.76 \%$ of the study population had family history of Diabetes. HbA1C level is used as a marker of glycaemic control. The average HbA1c of the study population was $8.53 \%$. Among the study population, $20.03 \%(n=250), 47.03 \%(n=587)$ and $32.93 \%(n=411)$ of the subjects had HbA1C was less than $7 \%$, between 7.1 to $9 \%$ and more than $9 \%$ respectively. Clinical data and demographic characteristics were summarized in Table 1.

There exist a significant difference in Hypertriglyceridemia among the various age groups (F-15.86; $\mathrm{p}=0.001)$, Likewise significant difference exist among the gender $(\mathrm{F}-8.02$; $\mathrm{p}=0.005)$ (Table 2). The age specific prevalence of isolated hyper Triglyceride, showed that there exist a significant difference among male and female and also among the age groups (Table3). Isolated Triglyceride levels shows a positive correlation with age $(\mathrm{r}=0.219 ; \mathrm{p}=0.000), \mathrm{Gender}(0.076 ; \mathrm{p}=0.008), \mathrm{HbA1C}(\mathrm{r}=0.104$; $\mathrm{p}=0.00$ ) as shown in Table 4 . 


\section{Discussion:}

Multifactorial disorders such as diabetes present a wide range of lipid abnormalities. Among T2DM individuals, the incidence of hyper triglyceride was high when compared to other lipid abnormalities $(14,15)$. The current study highlighted the existence of significant correlation among HbA1C, Gender, and age with hypertriglyceridemia. This may aid in predicting the status of triglyceride among T2DM individuals from the level of glycaemic control and consequently helps in picking up the patients who are at increased risk from CVD events $(16,17)$. Diabetes itself is an independent risk factor for CVD, and it is one of the common cause for mortality among diabetes patient $(18,19)$. The current study finding ighlighted that the poor glycaemic control increases the risk of isolated triglyceride (20). The correlation of Glycated Haemoglobin with isolated hyper triglyceride, showed that it is direct marker for hypertriglycerimia, further it would be the indirect marker of risk assessment of CVD. The need of the hour is to increase the awareness among the clinicians about the relationship among isolated triglyceride and poorly controlled $\mathrm{HbA1C}$ in T2DM individuals. Hence the clinicians should be careful in monitoring the fasting triglycerides level in patients with poorly controlled glycaemic levels.

Isolated triglyceride, is common among individuals with T2DM in spite of taking statins. The findings of the current study is in line with the earlier studies $(21,22)$. The prevalence of isolated hyper triglyceride was higher in earlier studies, when compared to the current study (23-25). Further there exist a significant correlation between the Glycated haemoglobin and isolated triglyceride. This finding is in line with the study conducted by Naqvi et al., (26). Reduce-It trail emphasized the cardiovascular benefits by controlling Triglyceride and other lipid lowering therapies (27). To reduce triglyceride levels and achieve glycaemic control, lifestyle changes are equally important for patients with T2DM. According to earlier studies, patients who can lose 5-10\% of their body weight experience a significant reduction in triglyceride (25\%), further it is creates a greater impact on glycaemic levels (28, 29).

In combination with low carbohydrate consumption, a diet high in unsaturated fat and protein lowers triglyceride levels (30). It is well known that carbohydrates increase TG levels in general. Interestingly, a reduction in carbohydrate consumption led to a lower TG level and a reversed metabolic syndrome based on a recently concluded randomized controlled trial (31 -33). Likewise resistance and aerobic exercises also exhibits a beneficial effect in lowering TG levels $(34,35)$. Patients with T2DM are at a higher risk of dyslipidaemia. The condition of dyslipidaemia and the associated risks should be explained to all patients with T2DM. In addition to monitoring blood sugar levels regularly, monitoring the lipid profile is also essential for assessing and treating dyslipidaemia. This could dramatically reduce the cardiovascular morbidity and mortality among T2DM patients.

Irrespective of the strength of the study such as sample size, relatively heterogeneous samples of general population, there are major limitation such as, the study lacks the longitudinal follow-up of the patient. Even though the Glycated haemoglobin has significant impact on isolated triglyceride, it is not enough to derive a conclusion on the correlation and association using this cross sectional study. Further multicentre study is necessary to derive a conclusion and consolidate the existing knowledge on this topic in local settings. Despite these limitations, the present provided the valuable data on hypertriglyceridemia among T2DM patients among Indian population.

\section{Conclusion:}

A considerable amount of T2DM individuals have isolated triglyceride and they remains a high risk category for CVD risk. The need of the hour is that the future research should focus on the isolated triglyceride among T2DM individuals who are at higher risk for CVD. The current study highlights the control of Glycated haemoglobin in prevention of isolated triglyceride. The proper control of Glycated haemoglobin might prevent the predisposition of isolated triglyceride and reducing the risk of cardiovascular disease. To conclude, the long term study should be encouraged along with the specific screening strategies at the 
early stage of diabetes and should focus on the health dietary habits, exercise and medications. An exclusive multidisciplinary approach is needed for dyslipidemia and specifically for isolated hyper triglyceride should be encourage during the visit with Diabetologist and diabetes educators should play a major role in creating awareness among patients with diabetes in developing country like India. Thus timely screening and monitoring is needed to reduce the CVD risk among T2DM individuals.

\section{References:}

1. Whiting DR, Guariguata L, Weil C, Shaw J. IDF diabetes atlas: global estimates of the prevalence of diabetes for 2011 and 2030. Diabetes Res Clin Pract 2011; 94:311-21.

2. Lee J, Son H, Ryu OH: Management status of cardiovascular disease risk factors for dyslipidemia among Korean adults. Yonsei Med J. 2017, 58:326-338.

3. Dake AW, Sora ND: Diabetic dyslipidemia review: an update on current concepts and management guidelines of diabetic dyslipidemia. Am J Med Sci. 2016, 351:361-365.

4. Leiter LA, Lundman P, da Silva PM, Drexel H, Junger C, Gitt AK. Persistent lipid abnormalities in statin-treated patients with diabetes mellitus in Europe and Canada: results of the Dyslipidaemia International Study. Diabet Med 2011; 28:134351.

5. Hirano T. Pathophysiology of Diabetic Dyslipidemia. J Atheroscler Thromb 2018; 25:771-82.

6. Enas EA, Yusuf S, Mehta JL. Prevalence of coronary artery disease in Asian Indians. Am J Cardiol 1992;70:945-9.

7. Sharma KH, Sahoo S, Shah KH, Patel AK, Jadhav ND, Parmar MM, et al. Are Gujarati Asian Indians 'older' for their 'vascular age' as compared to their 'Chronological age'? QJM 2015;108:105-12.

8. India State-Level Disease Burden Initiative CVD Collaborators, The changing patterns of cardiovascular diseases and their risk factors in the states of India: The Global Burden of Disease Study 1990-2016, The Lancet 2018, 6 (12), E1339-E1351.

9. Quispe R, Martin SS, Jones SR: Triglycerides to high-density-lipoprotein-cholesterol ratio, glycemic control and cardiovascular risk in obese patients with type 2 diabetes. Curr Opin Endocrinol Diabetes Obes. 2016, 23:150-156.

10. Ren Y, Luo X, Wang C, et al.: Prevalence of hypertriglyceridemic waist and association with risk of type 2 diabetes mellitus: a meta-analysis. Diabetes Metab Res Rev. 2016, 32:405-412.

11. Ullah Z, Malik SE, Ghaffar T, Kanawal S, Noor A, Aamir AH. Frequency of hypertriglyceridemia in type 2 diabetic patients receiving statin therapy and its correlation with glycemic control. J Postgrad Med Inst 2020; 34(4): 253-7

12. Chen GY, Li L, Dai F, et al.: Prevalence of and risk factors for type 2 diabetes mellitus in hyperlipidemia in China. Med Sci Monit. 2015, 21:2476-2484.

13. Roy S, Sherman A, Monari-Sparks MJ, et al.: Association of comorbid and metabolic factors with optimal control of type 2 diabetes mellitus. N Am J Med Sci. 2016, 8:31-39.

14. Ozder A: Lipid profile abnormalities seen in T2DM patients in primary healthcare in Turkey: a cross sectional study. Lipids Health Dis. 2014, 13:183.

15. Patel VI, Patel KP, Makadia MG, et al.: Levels of apolipoprotein a1, b100 and lipoprotein (a) in controlled and uncontrolled diabetic patients and in non-diabetic healthy people. J Clin Diagn Res. 2017, 11:01-05.

16. Mortensen LS, Hartvigsen ML, Brader LJ, et al.: Differential effects of protein quality on postprandial lipemia in response to a fat-rich meal in type 2 diabetes: comparison of whey, casein, gluten, and codprotein. Am J Clin Nutr. 2009, 90:4148.

17. Lebovitz HE, Ludvik B, Yaniv I, et al.: Fasting plasma triglycerides predict the glycaemic response to treatment of type 2 diabetes by gastric electrical stimulation. A novel lipotoxicity paradigm. Diabetic Med. 2013, 30:687-693. 
18. Valensi P, Avignon A, Sultan A, et al.: Atherogenic dyslipidemia and risk of silent coronary artery disease in asymptomatic patients with type 2 diabetes: a cross-sectional study. Cardiovasc Diabetol. 2016, 15:104.

19. Schofield JD, Liu Y, Rao-Balakrishna P, et al.: Diabetes dyslipidemia. Diabetes Ther. 2016, 7:203-219.

20. Srikanth S, Deedwania P: Management of dyslipidemia in patients with hypertension, diabetes, and metabolic syndrome. Curr Hypertens Rep. 2016, 18:76.

21. Fan W, Philip S, Granowitz C, Toth PP, Wong ND. Prevalence of US Adults with triglycerides $\geq 150 \mathrm{mg} / \mathrm{dl}:$ NHANES 2007-2014. Cardiol Ther 2020; 9:207-13.

22. Oh RC, Lanier JB. Management of hypertriglyceridemia in statin-treated type 2 diabetic patient. Am Fam Physician 2007; 75:1365-71.

23. Feher M, Greener M, Munro N. Persistent hypertriglyceridemia in statin-treated patients with type 2 diabetes mellitus. Diabetes Metab Syndr Obes 2013; 6:11-5.

24. Bruckert E, Baccara-Dinet M, Eschwege E. Low HDL-cholesterol is common in European Type 2 diabetic patients receiving treatment for dyslipidaemia: data from a pan-European survey. Diabet Med 2007; 24:388-91.

25. Al Sifri SN, Almahmeed W, Azar S, Okkeh O, Bramlage P, Jünger C et al. Results of the dyslipidemia international study (DYSIS)-Middle East: clinical perspective on the prevalence and characteristics of lipid abnormalities in the setting of chronic statin treatment. PLoS One 2014; 9:e84350.

26. Naqvi S, Naveed S, Ali Z, Ahmad SM, Khan RA, Raj H et al. Correlation between glycated hemoglobin and triglyceride level in type 2 diabetes mellitus. Cureus 2017; 9:e1347.

27. Bhatt DL, Steg PG, Miller M, Brinton EA, Jacobson TA, Ketchum SB et al. Cardiovascular risk reduction with icosapent ethyl for hypertriglyceridemia. N Engl J Med 2019; 380:11-22.

28. Wing RR, Lang W, Wadden TA, Safford M, Knowler WC, Bertoni AG et al. Benefits of modest weight loss in improving cardiovascular risk factors in overweight and obese individuals with type 2 diabetes. Diabetes Care 2011; 34:1481-6.

29. Maraki MI, Aggelopoulou N, Christodoulou N, Anastasiou CA, Toutouza M, Panagiotakos DB et al. Lifestyle intervention leading to moderate weight loss normalizes postprandial triacylglycerolemia despite persisting obesity. Obesity $2011 ; 19: 968-76$.

30. Appel LJ, Sacks FM, Carey VJ, Obarzanek E, Swain JF, Miller ER et al. Effects of protein, monounsaturated fat, and carbohydrate intake on blood pressure and serum lipids: results of the omniheart randomized trial. J Am Med Assoc 2005; 294:2455-64.

31. Hyde PN, Sapper TN, Crabtree CD, La Fountain R, Bowling M, Buga A et al. Dietary carbohydrate restriction improves metabolic syndrome independent of weight loss. J Clin Invest Insight 2019; 4:e128308.

32. Berglund L, Brunzell JD, Goldberg AC, Goldberg IJ, Sacks F, Murad MH et al. Evaluation and treatment of hypertriglyceridemia: an endocrine society clinical practice guideline. J Clin Endocrinol Metab 2012; 97:2969-89.

33. 2019 ESC/EAS Guidelines for the management of dyslipidaemias: lipid modification to reduce cardiovascular risk. Eur Heart J 2020; 41:111-88.

34. Gordon B, Chen S, Durstine JL. The effects of exercise training on the traditional lipid profile and beyond. Curr Sports Med Rep 2014; 13:253-9.

35. Mann S, Beedie C, Jimenez A. Differential effects of aerobic exercise, resistance training and combined exercise modalities on cholesterol and the lipid profile: review, synthesis and recommendations. Sports Med 2014; 44:211-21.

Table 1: General and Biochemical Characteristics of the study population: 


\begin{tabular}{|c|c|c|c|c|c|}
\hline \multirow{2}{*}{$\frac{\text { S.NO }}{1}$} & \multicolumn{2}{|c|}{ Variables } & \multirow{2}{*}{$\begin{array}{l}\text { Male }(\mathrm{n}=801) \\
79(9.8 \%)\end{array}$} & \multirow{2}{*}{\begin{tabular}{|l|} 
Female $(\mathrm{n}=447)$ \\
$22(4.92 \%)$
\end{tabular}} & \multirow{2}{*}{\begin{tabular}{|l|} 
Total $(\mathrm{n}=1248$ \\
$102(8.17 \%)$ \\
\end{tabular}} \\
\hline & \multirow[t]{5}{*}{ Age } & $30-39$ & & & \\
\hline & & $40-49$ & $172(21.47 \%)$ & $67(14.98 \%)$ & \begin{tabular}{|l|}
$239(19.15 \%)$ \\
\end{tabular} \\
\hline & & $50-59$ & $228(28.46 \%)$ & $151(33.78 \%)$ & \begin{tabular}{|l|}
$379(30.36 \%)$ \\
\end{tabular} \\
\hline & & $60-69$ & $218(27.21 \%)$ & $134(29.97 \%)$ & $352(28.20 \%)$ \\
\hline & & $70-79$ & $104(12.98 \%)$ & $72(16.10 \%)$ & $176(14.10 \%)$ \\
\hline & \multicolumn{2}{|c|}{ Mean Age } & $56.045 \pm 12.91$ & $58.358 \pm 11.012$ & $56.873 \pm 12.309$ \\
\hline 2 & \multicolumn{2}{|c|}{ Duration of DM } & $18.56 \pm 5.62$ & $15.19 \pm 6.27$ & $15.87 \pm 5.92$ \\
\hline 3 & \multicolumn{2}{|c|}{ Family History of DM } & $654(81.64 \%)$ & $354(79.19 \%)$ & $1008(80.76 \%)$ \\
\hline \multirow[t]{2}{*}{4} & \multirow[t]{2}{*}{$\mathrm{BP}$} & SBP & $135.25 \pm 20.59$ & $137 \pm 18.25$ & \begin{tabular}{|l|}
$136.52 \pm 19.36$ \\
\end{tabular} \\
\hline & & DBP & $85.24 \pm 10.25$ & $82.56 \pm 12.54$ & $53.26 \pm 11.49$ \\
\hline 5 & \multicolumn{2}{|l|}{ HbA1c } & $8.47 \pm 1.75$ & $8.65 \pm 1.82$ & $8.53 \pm 1.78$ \\
\hline \multirow[t]{3}{*}{6} & \multirow{3}{*}{$\begin{array}{l}\text { HbA1c } \\
\text { group }\end{array}$} & $\leq 7$ & $167(20.84 \%)$ & $83(18.56 \%)$ & $250(20.03 \%)$ \\
\hline & & \begin{tabular}{|l|}
$7.1-9$ \\
\end{tabular} & $378(47.19 \%)$ & $209(46.75 \%)$ & \begin{tabular}{|l|}
$587(47.03 \%)$ \\
\end{tabular} \\
\hline & & $\geq 9$ & $253(31.58 \%)$ & $158(35.34 \%)$ & $411(32.93 \%)$ \\
\hline 7 & \multicolumn{2}{|c|}{ Triglyceride } & $305.66 \pm 143.03$ & $282.94 \pm 110.5$ & $297.14 \pm 132.68$ \\
\hline
\end{tabular}

Table 2: Descriptive statistics of the study participants

\begin{tabular}{|c|c|c|c|c|c|}
\hline \multicolumn{2}{|l|}{ Variable } & \multirow{3}{*}{$\begin{array}{l}\mathrm{N} \\
102\end{array}$} & \multicolumn{3}{|l|}{ Triglyceride } \\
\hline & & Mean \pm SD & F- Value & P Value \\
\hline \multirow[t]{5}{*}{ Age } & $30-39$ & & $331.78 \pm 152.91$ & \multirow[t]{5}{*}{15.864} & \multirow[t]{5}{*}{$0.001 *$} \\
\hline & $40-49$ & 239 & $363.43 \pm 211.34$ & & \\
\hline & $50-59$ & 379 & $259.6 \pm 135.86$ & & \\
\hline & $60-69$ & 352 & $275.13 \pm 97.919$ & & \\
\hline & $70-79$ & 176 & $261.05 \pm 71.98$ & & \\
\hline \multirow[t]{2}{*}{ Gender } & Male & 801 & $305.66 \pm 143.03$ & \multirow[t]{2}{*}{8.023} & \multirow[t]{2}{*}{$0.005^{*}$} \\
\hline & Female & 447 & $282.94 \pm 110.5$ & & \\
\hline \multirow[t]{3}{*}{$\mathrm{HbA1C}$} & $\leq 7$ & 250 & $285.89 \pm 139.43$ & \multirow[t]{3}{*}{12.675} & \multirow[t]{3}{*}{$0.000^{*}$} \\
\hline & $7.1-9$ & 587 & $283.33 \pm 103.32$ & & \\
\hline & $\geq 9$ & 411 & $324.15 \pm 160.26$ & & \\
\hline
\end{tabular}

$*$ denotes the values are significant at $\mathrm{p}<0.05$

Table 3: Age specific prevalence of isolated Triglyceride

\begin{tabular}{|c|c|c|c|c|}
\hline Age & Male & P- value & Female & P- Value \\
\hline $30-39$ & $339.17 \pm 164.77$ & \multirow[t]{5}{*}{$0.0001^{*}$} & $313.55 \pm 147.17$ & \multirow[t]{5}{*}{$0.018^{*}$} \\
\hline $40-49$ & $377.01 \pm 224.93$ & & $314.26 \pm 117.11$ & \\
\hline $50-59$ & $299.56 \pm 140.06$ & & $289.82 \pm 129.76$ & \\
\hline $60-69$ & $281.47 \pm 106.94$ & & $265.04 \pm 80.89$ & \\
\hline $70-79$ & $256.35 \pm 55.035$ & & $267.83 \pm 91.116$ & \\
\hline
\end{tabular}

Table 4: Correlation analysis of the study variables:

\begin{tabular}{|l|l|l|}
\hline Variables & Triglyceride & p- Value \\
\hline Age & $0.219^{* *}$ & 0.000 \\
\hline Gender & $0.076^{* *}$ & 0.008 \\
\hline HbA1c & $0.104^{* *}$ & 0.000 \\
\hline
\end{tabular}

** Pearson Correlation is significant at $\mathrm{p}<0.001$ 